\title{
Don't Forget the Fungi When Considering Global Catastrophic Biorisks
}

\author{
Arturo Casadevall
}

$\mathrm{W}$ HEN IT COMES TO biodefense and preparedness, the fungal kingdom is often a late afterthought. For example, among the original agents in the select agents list that were pathogenic for humans, only one fungus, Coccidioides immitis, was included, but the same organism was initially left out of the NIH priority agents list. This made laboratories working on this important pathogenic fungus subject to all the select agent regulations without the benefits of being able to apply for biodefense money. Although in recent years this fungus was taken off the select agents list and added to the NIH priority list, this anecdote is evocative of the way that this fungal kingdom is often forgotten when considering global catastrophic biological risks (GCBRs).

In fairness to policymakers and preparedness experts, there has always been great concern about fungal threats to agriculture. However, when it comes to humans and animals, the potential threats from the fungal world are often ignored. Part of this obliviousness reflects the fact that fungal diseases are generally not communicable among humans and that immunologically intact humans are seldom susceptible to invasive mycoses. Hence, humanity does not have an experience with fungal pathogens comparable to the types of plagues caused by viral and bacterial diseases and consequently tends to ignore the fungal kingdom when assessing threats.

The blind spot with regard to fungi is paradoxical given that fungal pathogens are currently devastating entire ecosystems. ${ }^{1}$ Examples of the calamities caused by fungi include: (1) the extinction of numerous amphibian species as a result of infection with a chytrid fungus; (2) the decimation of North American bats by fungal disease new to the Americas; and (3) salamander, turtle, and snake die-offs from new fungal diseases.

In general, humans and most mammals are remarkably resistant to invasive fungal diseases. The source of this re- sistance is believed to be a combination of adaptive immunity and endothermy, which effectively creates a thermal restriction zone that excludes the majority of fungal species. ${ }^{2}$ However, the prevalence of fungal diseases can increase dramatically in human populations when there is an impairment of immunity, as evident from the high prevalence of cryptococcosis, candidiasis, and histoplasmosis in patients with AIDS. In fact, fungal diseases are now quite common, as a combination of medical progress, which often comes at the price of impaired immunity, and the global cataclysm of the HIV epidemic. With regard to the latter, cryptococcosis is now one of the major causes of death in sub-Saharan Africa, given the high prevalence of HIV infection in those populations. ${ }^{3}$

In the past few years we have witnessed the emergence of a new fungal pathogen in Candida auris. This organism is associated with systemic infections that are resistant to many of the available antifungal drugs. ${ }^{4} C$. auris may be a harbinger of things to come. The low susceptibility of mammals to fungal diseases is determined largely by the temperature gradient between mammalian temperatures and temperatures tolerated by most fungal species. ${ }^{5}$ However, as the world warms with climate change, many fungal species with the potential for pathogenicity in mammals will adapt to higher temperatures and could thus pose threats to human health. ${ }^{6}$

There is an old adage that generals often prepare to fight the last war. This adage is relevant because most analysis of biological threats is heavily weighted toward concern for those viral and bacterial risks that we know about - the last wars. As we prepare to confront global catastrophic biorisks, we must consider the possibility that new threats from the fungal kingdom will be the future wars.

(C) Arturo Casadevall, 2017; Published by Mary Ann Liebert, Inc. This Open Access article is distributed under the terms of the Creative Commons Attribution Noncommercial License (http://creativecommons.org/licenses/by-nc/4.0/) which permits any noncommercial use, distribution, and reproduction in any medium, provided the original author(s) and the source are credited. 


\section{REFERENCES}

1. Fisher MC, Henk DA, Briggs CJ, et al. Emerging fungal threats to animal, plant and ecosystem health. Nature 2012; 484(7393):186-194.

2. Casadevall A. Fungi and the rise of mammals. PLoS Pathog 2012;8(8):e1002808.

3. Park BJ, Wannemuehler KA, Marston BJ, Govender N, Pappas PG, Chiller TM. Estimation of the current global burden of cryptococcal meningitis among persons living with HIV/AIDS. AIDS 2009;23(4):525-530.

4. Chowdhary A, Sharma C, Meis JF. Candida auris: a rapidly emerging cause of hospital-acquired multidrug-resistant fungal infections globally. PLoS Pathog 2017;13(5):e1006290.
5. Robert VA, Casadevall A. Vertebrate endothermy restricts most fungi as potential pathogens. J Infect Dis 2009;200(10): 1623-1626.

6. Garcia-Solache MA, Casadevall A. Global warming will bring new fungal diseases for mammals. MBio 2010;1(1).

Arturo Casadevall, $M D$ Chair, Molecular Microbiology \& Immunology Johns Hopkins Bloomberg School of Public Health 615 N. Wolfe Street

Baltimore, MD 21205

Email: acasade1@jhu.edu 